\title{
GRAAF VER HUELL IN GUYANA
}

DOOR

JHR. L. C. VAN PANHUYS

Directeuren en Regeerders van Suriname, zoo zegt Wolbers in zijn uitvoerige geschiedenis van de kolonie blz. 445 , hadden bij het vernemen van den slavenopstand op St. Domingo besloten twee oorlogschepen naar Suriname te zenden, ten einde aan de volkplanters bij een dergelijke gebeurtenis de noodige bescherming te verleenen. Volgens de extraordinaire notulen van Gouverneur en Raden, rakende de binnen- en buitenlandsche defensie van Suriname, van 10 April 1792 besloot het Hof echter om aan Directeuren en Regeerders in 't moederland te berichten, dat men dergelijke hulp niet noodig had. Klaarblijkelijk omdat men zich in Suriname geheel veilig achtte, want juist op dat oogenblik waren de Bonni-negers, onder het gevreesde opperhoofd van dien naam met behulp van de bevredigde Aucaner-Boschnegers of Djocka's geheel overweldigd. Toen dan ook eenige dagen later de luitenant ter zee Ver Huell voor de stad Paramaribo aankwam met 's Lands oorlogsbrik de Pijl om de aangeboden hulp te verleenen, bedankte men hem beleefdelijk, waarop hij koers zette naar Berbice.

De beknopte geschiedenis van Suriname van mejuffrouw Vlier en het overzicht van die geschiedenis van Thomson maken, evenmin als de geschiedenis van Essequebo, Demerary en Berbice van generaal Netscher, gewag van de bezoeken aan de vier koloniën, door Ver Huell bij wijze van voorzorg gebracht. De beschrijving van (of namens) Ver Huell van die bezoeken werpt echter een eigenaardig licht op toestanden, verhoudingen en denkbeelden van den tijd en het bijzondere is, dat die beschrijving eerst het licht heeft gezien vijf en vijftig jaar, nadat de bezoeken plaats vonden. Want eerst in 1847 liet de kapitein ter zee, Q. M. Ver Huell te Amsterdam (bij G. J. A. Beyerinck) een boek verschijnen, getiteld: Het leven en karakter van Carel Hendrik Graaf Van

$$
-81-
$$

West-Indische Gids XXV 
Ver Huell (deze was zijn oom), uit nagelaten aanteekeningen en authentieke stukken, 2 deelen, met portret en platen. Vermoedelijk is noch in Suriname, noch in Britsch Guyana dit boek bekend geworden. Het relaas van de bezoeken aan Nederlandsch Guyana in 1792 ligt in de bladzijden 55-80 van het boek verborgen.

Reeds uit de inleiding kan men zich een denkbeeld van de persoon van Ver Huell vormen. Daarin staat, dat hij, toen hij schout bij nacht werd, vier en twintig jaar bij de zeemacht had gediend en alle rangen had doorloopen, voorts dat hij in 1803 aan het hoofd stond van de Nederlandsche zeemacht en in 1805 minister van Marine was. Uit den aanvang van het boek blijkt, dat hij reeds op zeventienjarigen leeftijd werd bevorderd tot luitenant ter zee titulair en in dien rang den slag bij Doggersbank medemaakte, voor welk wapenfeit koning Willem I hem, als een van de weinigen, die nog waren overgebleven, op hoogen leeftijd het ridderkruis van de Militaire Willemsorde door den kapitein ter zee Van Karnebeek heeft doen overhandigen.

Het is niet de plaats om over den veelbewogen levensloop van Ver Huell meer te schrijven, maar wel om, zooals gezegd, het een en ander te vermelden over zijn bezoeken, in 1792 aan Suriname en het latere Britsch Guyana gebracht.

Nadat hij zich als eerste officier op een nabij Den Helder als wacht- en artillerieschip dienstdoend fregat, de Maria Louisa, van 54 stukken, onder kapitein Cambier door vurigen ijver en bekwaamheid had onderscheiden, werd hem in den zomer van 1791 het (zelfstandig) bevel opgedragen van het fregat de Lynx, doch bij een hevigen nachtelijken brand in het groote magazijn op de werf te Amsterdam werden de zeilen en wat verder tot de uitrusting van de Lynx behoorde een prooi der vlammen, zoodat dit schip vooreerst niet in dienst kon gesteld worden. Eenige maanden later verkreeg Ver Huell het bevel over de brik de $P$ ijl, van 16 stukken, bemand met 80 koppen, en hij ontving van den Prins den last zich met die brik naar West Indië te begeven en er onze bezittingen aan de kust van Guyana aan te doen. De dringendste bevelen noodzaakten hem in de maand December van Texel uit te zeilen, maar de brik werd door tegenwind en storm tweemalen er toe verplicht weder binnen te loopen; later om te Torbay stormschade te laten herstellen en voorts nog om te Plymouth een schuilplaats te zoeken. Eerst 16 Februari geraakte de Pijl uit het Kanaal, den 11 den Maart kreeg men de Canarische eilanden in 't zicht, en het bleek noodig zich daarna nog op een van de kaap-Verdische eilanden van drinkwater te voorzien. 
Den 4den April daagde (eindelijk) de kust van Guyana in het verschiet en den 7den stuurde de Pijl de Suriname-rivier binnen. De schoone natuur en de wel beplante plantages maakten met de welvaart, die er scheen te heerschen, een zeer aangenamen indruk.

Den volgenden dag voor Paramaribo voor anker komend, begaf Ver Huell zich bij Gouverneur Frederici, waar hij zeer beleefd ontvangen en dien middag ten eten genoodigd werd. Hier werd hem een brief van den kapitin ter zee Laurens Spengler overhandigd, die het bevel voerde over het fregat Alliantie, eenige dagen te voren naar Demerary gestevend, en inhoudende den last van den Prins zich onder zijn bevelen te stellen, tevens Berbice en Demerary aan te doen en aldaar te vertoeven, zoolang de regeering zulks noodzakelijk zou oordeelen.

Slechts weinige dagen vertoefde Ver Huell te Paramaribo. De militaire staat der kolonie scheen hem wel onderhouden toe. Dit oordeel klopt niet met de verzekering van Wolbers (blz. 452), dat zich in 1793 in Suriname slechts één oorlogschip bevond, en de andere verdedigingsmiddelen gering en bovendien nog in slechten staat waren. Ook niet wel met Frederici's wensch om in 1795 , de kolonie in een goed verdedigbaren toestand te brengen (Wolbers, blz. 455). Vóór Ver Huell's zienswijze pleit weer tot op zekere hoogte, dat, toen in 1795 in Demerary een opstand onder de slaven was uitgebroken, een korps van 50 soldaten en 25 man van het legercorps, onder bevel van luitenant kolonel Stoelman in Augustus van Suriname naar Demerary gezonden, in December naar Suriname terugkeeren kon, omdat met behulp van dit korps de opstand was onderdrukt (Wolbers, 464). Intusschen moet men in 't oog houden, dat er heel wat meer vereischt werd om een buitenlandschen inval te keeren dan om een oproerige slavenmacht te bedwingen.

Ver Huell's verblijf in de kolonie, zoo staat er aan het slot van het relaas, was te kort om de geheele waarde van deze zoo hoogst belangrijke bezitting te leeren kennen, die, voor groote uitbreiding vatbaar, alleen achterlijk bleef uit gebrek aan den gunstigen geest van aanmoediging, welke te voren onze natie van andere onderscheidde, en die hier bijna geheel uitgedoofd scheen.

Is hier Ver Huell zelf aan het woord of zijn neef, den bewerker van zijn aanteekeningen? Wij vermoeden het eerste, omdat het uitgesproken ongunstige oordeel zoo zeer overeenkomt met hetgeen Ver Huell over Berbice, Demerary en Essequebo opmerkt. 
Op een plaats vat hij zijn ongunstige indrukken samen en dan noemt hij daarbij Suriname evenzeer. In geen der koloniën Suriname, Berbice, Demerary en Essequebo kon men uitzichten tot uitbreiding waarnemen, staat er letterlijk. De Engelschen hadden alleen daarvan nog treffelijke sporen nagelaten in de kolonie, die zij het langst in het bezit hadden gehad na den oorlog van 1780. In Demerary bespeurde men echter wat meer nijverheid, en het waren de aldaar gebleven Engelsche eigenaren, die daarvan het voorbeeld gaven. Hij genoot in Demerary vele bewijzen van gulle gastvrijheid, schrijft hij, en verkreeg daardoor een meer grondige kennis der kolonie en van de gebreken in de administratie, waaraan hij de weinige aanmoediging toeschreef om de koloniën uit te breiden. Terwijl de Engelschen gedurende den tijd, dat zij in het bezit ervan waren geweest, aanmerkelijke stappen voorwaarts hadden gedaan, was nu alles weder ingesluimerd en veronachtzaamd. Demerary en Essequebo konden als één kolonie beschouwd worden, die vatbaar zou zijn voor groote uitbreiding en geschikt was tot het aankweeken van allerlei producten. De grenzen waren niet bepaald en konden zoo ver uitgestrekt worden als de rivieren bevaarbaar zijn. Op een tochtje naar Essequebo is Ver Huell verwonderd over de weinige bedrijvigheid in dat gewest, geen tiende, ja zelfs geen twintigste, gedeelte dezer kolonie was bebouwd. Toen hij bij den heer Backer, Gouverneur van Demerary op diens plantage, aan den mond der rivier gelegen, kwam, vond hij gelegenheid meer van den waren toestand der kolonie te vernemen, en werd hij in zijn meening omtrent den toestand langs de bovenrivieren versterkt, namelijk dat alle plantages aldaar weldra geheel en al verlaten zouden zijn. Deze zoo zonderlinge nalatigheid, vervolgt hij, van een ijverige en werkzame natie als de Hollandsche, onder een goede en vaderlijke regeering, kon nergens anders aan toegeschreven worden dan aan de slordigheid en achteloosheid der West-Indische Compagnie, die zonder uitsluiting het gezag (het monopolie) over die volkplantingen wilde behouden, en allen geest van onderneming scheen tegen te werken.

Van Suriname zeilde de Pijl dus naar de kolonie Berbice, waar Ver Huell met veel onderscheiding ontvangen werd. De fiscaal en een officier, door den gouverneur Imbyze van Batenburg afgevaardigd, kwamen de brik tegenmoet om den bevelhebber met de behouden aankomst geluk te wenschen, en tevens te verzoeken tot voor het hoofdfort Nassau op te werken, ten einde ontzag 
aan de negerbevolking in te boezemen. Men scheen namelijk beducht (dezelfde beduchtheid die volgens de aanhef van ons opstel ook bij Directeuren en Regeerders in 't moederland bestond) dat de bewegingen die onder de negers van S. Domingo waren ontstaan, ook in Guyana weerklank zouden kunnen vinden; de negerslaven zouden er in de woeste binnenlanden kunnen trekken en zich zoodanig vastnestelen, dat het moeilijk zou zijn hen tot hun plicht terug te brengen. In Berbice was men dus vooral bevreesd, dat van de plantages weggeloopen slaven zich, evenals in Suriname, als Boschnegers in de landstreken aan de bovenrivieren zouden gaan ophouden.

Ongegrond was de vrees voor opstand in Berbice niet. Daar had men in 1763 bitter geleden onder een slavenopstand op groote schaal, die maar met veel moeite had kunnen worden bedwongen. Mr. J. J. Hartsinck heeft er in het eerste deel van zijn beschrijving van Guyana op blz. 371 tot 517 een zeer uitvoerig verslag van gegeven; en gen. Netscher in zijn aangehaald boek, blz. 196-243. Ver Huell, die allicht wel de redenen zal hebben vernomen, waarom hem zoo dringend was bevolen in de ongunstige Decembermaand van Texel uit te zeilen, aarzelde geen oogenblik om aan het verzoek van Gouverneur en Raden gevolg te geven; na 72 mijlen tusschen de met hoog geboomte bezette oevers te hebben voortgestevend, kwam hij voor de laatste plantage "Savonette", ten anker, waar men bezig was timmerhout voor de kolonie te vellen.

Ver Huell was getroffen door den rijkdom der natuur, die te schilderachtiger was doordat het land in deze streken hooger begon te worden. De directeur van den post gaf hem te kennen dat zich verscheidene Indiaansche gezinnen in den omtrek tijdelijk hadden gevestigd; men hoorde het geluid hunner speeltuigen met groot geraas door de bosschen weerklinken. Hij noodigde Ver Huell met zijn officieren uit hem in de eenzame wouden te vergezellen, daar hij voornemens was ,deze wilde horden” op rum en brandewijn te onthalen en eenige geschenken onder hen uit te deelen; dit werd des avonds aan de Indianen plechtig aangekondigd.

Den volgenden dag was alles reeds vóór daglicht in beweging; men vernam een groot geraas en getier in de bosschen. Zoodra de dag aanbrak, zegt Ver Huell, maakten ,,de woeste benden" zich gereed het feest te vieren, doch niet voor omstreeks negen uur nam de statige optocht een aanvang. Een lange rij van mannen, voorzien van pijl, boog en strijdknods, en eenige vrouwen trokken 
onder een luidruchtig geschreeuw langs den directeur en Ver Huell heen. Een aanspraak van den directeur beoogde hen tot het werk aan te moedigen en verwekte veel tevredenheid en de belofte met het werk ijverig voort te gaan. De directeur liet in een zeer hoogen boom lappen blauw katoen, zijden stoffen, spiegeltjes en kralen ophangen als prijzen bij het boogschieten op een op zeventig pas opgestelde schijf; de winners mochten de prijzen zelf uit den boom halen. De schijf werd over 't algemeen zeer goed getroffen. De meeste mannen waren in feestdos, op ,,afzichtelijke wijze", zegt Ver Huell, met roode en witte verfstof besmeerd; hun haren glommen van kokosolie en waren met vederen versierd. Sommigen droegen mutsen van vogelveeren. $\mathrm{Na}$ den wedstrijd toog de bende onder hetzelfde geraas en getier naar een andere plaats waar allen gingen zitten, terwijl de vrouwen uit haar schuilplaatsen te voorschijn kwamen. Die waren eenvoudiger versierd, ze waren allen naakt behalve een klein schortje. Zij hadden veel zorg besteed aan het vlechten van heur gitzwart haar, dat zij met kralen en soms met zilveren lovertjes hadden doorstikt.

$\mathrm{Nu}$ nam het bovenmatig drinken van rum en brandewijn een aanvang; het geschreeuw vermeerderde nog allengs en daarna begon iedere volkstam op zijn eigen manier te dansen; het waren Warauen, Arowakken en Akowijers, die steeds van elkander afgezonderd bleven. De Arowakken waren het luidruchtigst en 't meest vroolijk; de Akowijers dansten allen tegelijk in een kring en bootsten het geluid van vele dieren na, terwijl zij nu en dan eenige woorden zongen die door allen in koor werden herhaald. De Warauen dansten meer ongeregeld. Eindelijk door den sterken drank bevangen, vielen de meesten van vermoeidheid in slaap.

Den volgenden dag vond Ver Huell gelegenheid de zeden dezer natuurmenschen nader te leeren kennen. Alvorens mede te deelen tot welke opmerkingen dit nader onderzoek leidde, nemen wij eerst gaarne even het exemplaar in prachtband van Among the Indians of Guiana van Sir E. F. im Thurn ter hand, dat de schrijver ons in 1912 bij gelegenheid van het AmericanistenCongres te zijnen huize te Londen, heeft geschonken. In dat van 1883 dagteekenende werk van groote betrouwbaarheid spelt de de kundige schrijver de namen van de reeds genoemdeIndianen stammen als volgt: Ackaowi, Arawak en Warrau (blz. 159). Wij zien, blz. 163, dat de Ackaowi tot de Caraïben behooren; de animositeit tusschen Caraïben en Arowakken verklaart de door Ver Huell opgemerkte afzondering tusschen de Akowijers en den 
laatstgenoemden stam. Er zullen voor den vakkundige nog wel aardige bijzonderheden uit de mededeelingen van Ver Huell zijn op te speuren. Mij trof, als amateur, de vermelding van huidversiering met witte verf, die $\mathrm{ik}$ bij im Thurn niet terugvond. Evenzoo - of heeft V.H. dit niet goed gezien? - zijn mededeeling, dat vezels van de kokosnoot zouden dienen bij de vervaardiging van een hangmat. Hoewel V.H. zich muziekinstrumenten, die bij de Indianen in gebruik waren heeft kunnen aanschaffen (blz. 64), heeft hij voor hun muziek geen andere woorden, dan dat de bosschen weergalmden van het luide geraas. Was het omdat V.H. een klassieke opleiding heeft gemist, dat hij het eenvoudige op dit gebied niet vermocht waar te nemen? Bleef hem het inzicht verborgen, dat een van de grootste Nederlandsche dichters in 1940 aldus uit in den bundel „Dagelijksch brood” (J. W. F. Weremeus Buning):

Met een van riet gesneden fluit

Heeft Dionysos het geluid

En Pan, onder de groene boomen

Het stampen van den dans vernomen

Muziek breekt allerwegen uit...

Het is of een laag van ras- en tijds-vooroordeelen Ver Huell belet den Indiaan een onafhankelijken en billijken maatstaf aan te leggen, wanneer hij zegt: dat hij bij deze ,woeste horden" (ditmaal een variatie van ,woeste benden") geen schijn van beschaving aantrof. Wat noemt Ver Huell beschaving? Een oogenblik blijft hij zichzelf echter dan niet gelijk, want hij verheft, naar het schijnt, den Indiaan weer hoog boven „,beschaafde”, slavenhoudende, onophoudelijk met elkander ruzie makende medemenschen, die elkander in den strijd om "meer verfijnde" bezittingen naar het leven staan, in dezen kostelijken volzin: „De geaardheid dezer volkeren is zeer zacht en toegevend; ,zij zijn zoodanig met hun lot en hunne leefwijze tevreden, dat ,zij volkomen onverschillig waren omtrent alles wat de Euro,peanen betrof, en geen de minste begeerte toonden, zich hun ",meer verfijnde bezittingen eigen te maken".

Ver Huell maakt melding van den verbouw van manioc en van het bakken van cassave; van het koken van de peperpot, en zegt o.a. zeer juist, dat de Indiaan zich met verf besmeert zoowel uit pronkzucht als om het steken van insecten tegen te gaan, hij deelt ook mede, dat gedurende het nachtverblijf door rook de insecten worden verdreven. Hij teekent aan, dat de Indianen op een plaats, die hun bevalt, hun hutten opslaan, en daar langer 
vertoeven, maar dat wanneer een hunner overlijdt, zij hem in de hut begraven en dadelijk het oord voor altijd verlaten. Onder de stammen, die zich toen ter plaatse bevonden, was geen opperhoofd, die eenig gezag uitoefende; hetgeen bleek toen het eene gezin na het andere weer het bosch introk, zonder op elkander acht te slaan. Er bestaat onder hen, zoo decreteert Ver Huell, geen verbintenis tusschen de beide geslachten; indien een paar elkander niet bevalt, dan scheiden zij. $\mathrm{Nu}$, wat deze laatste manier van doen betreft, zijn of schijnen er onder ons wel meer dan enkelen te zijn, die nu, aan 't eind van 1942, het beschavingsstandpunt van den Indiaan van 1792 hebben bereikt. Maar ik heb bezwaar tegen het zoo los neergeworpen, en zoo licht ook vluchtig gelezen zinnetje, inhoudende, dat onder de Indianen die V.H. bedoelt, geen verbintenis tusschen de beide geslachten bestaat. Het spreekt van zelf: bij een huwelijk tusschen Indianen, en naar gerust mag worden aangenomen ook onder de Indianen van V.H., is er geen huwelijksceremonieel, er wordt natuurlijk geen akte van den burgerlijken stand opgemaakt, de overheid bemoeit er zich niet mee; er wordt geen gelofte afgelegd en er worden geen ringen gewisseld. Maar een verbintenis tusschen beide geslachten bestaat er juist wel: die van wederzijdsche toegenegenheid, en die band is veel en veel hechter dan V.H. meent. Ik zeg dit niet zoo maar, op grond van de betrekkelijk weinige aanraking, die ik met Indianen in Suriname heb gehad, doch op grond van een mijns inziens hoogst belangrijk academisch proefschrift „Het huwelijk bij de ethnologische oervolken" ter verkrijging van den graad van doctor in de letteren en wijsbegeerte van T. W. Crul, geb. te Makasser. Ik wensch dit boek in handen van een ieder, die zich voor volkenkunde en de daarmede samenhangende wijsgeerige begrippen interesseert. Indien ik wist, dat iemand in Suriname (of Curaçao) een bibliotheek wilde oprichten, dan zou ik hem aan raden voor de volkenkundige afdeeling een groot deel van de naar gissing 240 boeken aan te schaffen, die in de litteratuur-opgaaf zijn vermeld.

Dr. Crul komt op grond van een bij een aantal primitieve volken ingesteld onderzoek tot de, zoover ik vermag te zien, onafwijsbare conclusie, dat de huwelijkskeus der ,ethnologische oervolken" vrij is, zoowel voor den jongen als het meisje; dat bij dit, één van de gewichtigste besluiten van het leven, zoowel de jongen als het meisje in gelijkwaardige positie verkeeren; dat naar de opvattingen van Schmidt en Koppers, (die ik beiden mocht ontmoeten) echtscheidingen bij deze volken zelden of niet voorkomen 
na de geboorte van een kind, en in 't laatste geval alleen dan wanneer man of vrouw zich misdraagt of de huwelijksplichten verwaarloost.

De goede bedoelingen van Ver Huell en het nobele van zijn denkwijze komen uit in zijn opmerking, dat de kolonisten zich niet met die Indianen bemoeiden, dan voor zoover zij hun hulp noodig hadden, en daardoor het verwijt verdienen geen pogingen aangewend te hebben om de beschaving bij die stammen veld te doen winnen. Eigenbaat en hebzucht hebben ons meester van die rijke gewesten gemaakt, en dit schijnt het eenige doel te zijn, dat men beoogt; hij gelooft, dat deze zachtaardige volken lichter te beschaven zouden zijn dan die der Zuidzee-eilanden.

Ver Huell begaf zich nog met den directeur in een kano, die op maatgezang van de Indianen vrij ver de rivier opwaarts pagaaide om een door de Indianen geschoten woud-ezel of groot wild zwijn te halen, waarvan het vleesch tot een aangenaam onthaal voor het scheepsvolk strekte. Twee jonge Indianen, van 16 tot 18 jaren, boden aan om met V.H. de reis mede te doen naar het land der blanken, dat met inwilliging van den directeur werd toegestaan. Zijn die Indianen in Nederland aangekomen? Daarover staat niets vermeld.

Ver Huell stelde zich nog de vraag, waarom zich hier niet eenige behoeftige Hollanders zouden vestigen, voorzien van gereedschappen om het land te ontginnen; zij zouden naar zijn meening met geringen arbeid meer dan het noodige voedsel vinden.

Korter kon het denkbeeld, waarover een heel boek zou kunnen worden geschreven, niet worden uitgedrukt. V.H. mag zich gelukkig prijzen dat men toen ter tijde niet gepoogd heeft het te verwezenlijken. De poging daartoe zou groote kans hebben gehad om op een groot verlies van menschenlevens uit te loopen. Want wel is het een feit, dat Schomburgh vele jaren in de binnenlanden van Britsch-Guyana heeft kunnen reizen zonder ziek te zijn geweest - wij vestigden daarop in 1904 de aandacht, noot blz. 430, voordrachten voor het Americanisten-Congres te Stuttgart - maar hij kwam dan alleen in aanraking met Indianen, en Nederlandsche kolonisten aan de Berbice rivier zouden vroeg of laat in de nabijheid zijn gekomen van uit Afrika afkomstige, in Berbice ingevoerde, negerslaven en dus zeer vermoedelijk geinfecteerd zijn geworden door met pernicieuse malariakiemen besmette muskieten.

Zooals gezegd, had Ver Huell zich Indiaansche muziekinstrumenten aangeschaft. Hij verwierf ook Indiaansche wapenen en 
andere voorwerpen; de directeur schonk hem eenige kisten met zeer schoone vlinders en insekten. Er bevond zich aldaar een Deensch hoogleeraar, Prof. Schmidt, door den Deenschen koning belast met het verzamelen van insekten, vogels en andere dieren. Deze geleerde deed dagelijks groote wandelingen in de bosschen en keerde telkens met een aanzienlijken buit terug.

De terugreis naar het fort Nassau was voorspoedig; nu en dan loste de brik een kanonschot om ontzag aan de negerslaven in te boezemen.

Nadat Ver Huell zich, om een misverstand op te helderen, met een klein vaartuig naar den kapitein ter zee Spengler had begeven, die zich met het fregat Alliantie in Demerary bevond, gaf deze hem den last den sluikhandel tegen te gaan en verder, nadat zijn victualietijd van negen maanden om zou zijn, zoo er zich geen omstandigheden voordeden, die zijn verblijf alhier noodzakelijk maakten, over Curaçao zijn thuisreis aan te nemen. Hij zou echter de kust niet dienen te verlaten, indien de voorvallen op St. Domingo een nadeeligen invloed op Demrary of Berbice mochten uitoefenen, al zou dan ook zijn victualie tijd om zijn. Ver Huell laveerde met zijn bootje terug naar de monding van de Berbice, waar de gouverneur hem tegemoet kwam. Binnen 24 uur zeilde nu de Pijlnaar Demerary,waar gouverneur en Raden hem eveneens met onderscheiding ontvingen. Spengler was reeds naar Curaçao vertrokken, doch was intusschen van plan veranderd. Ver Huell vond nu een bevel van zijn commandant om hem dadelijk naar Curaçao te volgen. De gouverneur verzocht hem echter eenigen tijd in Demerary te vertoeven om ontzag aan de slaven in te boezemen. Gouverneur en Raden legden tot staving van het verzoek en ter verantwoording van V.H. een officieel stuk over. Er bestond een geheime overeenkomst tusschen de negers der kolonie en die der eilanden; de drukke vaart van de Noord-Amerikanen had daartoe aanleiding gegeven; er werden samenscholingen gehouden en er werd een geest van onafhankelijkheid onder de slaven merkbaar. Van te meer belang was het dus, dat er een oorlogsvaartuig aanwezig bleef, waarmede de planters zeer waren ingenomen.

Op grond van den stelligen last van den Prins-Stadhouder om de koloniën niet te verlaten, zoo lang zijn verblijf aldaar van nut werd geoordeeld, bleef Ver Huell in Demerary. Hij verzekert, dat de behandeling van de slaven in deze kolonie veel zachter en menschelijker was dan in andere bezittingen op de kust van Guyana; vele planters wilden niet dulden, dat ze werden mis- 
handeld. Ver Huell, die voor eenige dagen zijn intrek had genomen bij den planter Copiers, op diens plantage "Goed Fortuin", deelt mede, dat deze aan anderen het voorbeeld gaf; nooit werd daar het klappen van de zweep gehoord en V.H. maakte er een voorval mede, dat hem de overtuiging schijnt te hebben gegeven, dat een rechtvaardige en humane behandeling zelfs op ruwe en onbeschaafde menschen zeer veel invloed heeft.

Op zekeren dag kwam de opzichter van de plantages met groote ontroering den heer Copiers berichten, dat de slaven van de drie mijlen hoogerop aan de rivier gelegen plantage ,de Hoop” in opstand waren en niet meer wilden gehoorzamen, omdat hij bevel gegeven had een groot deel van de slaven over te voeren naar een andere plantage „Providence”, die Copiers onlangs had gekocht en meer wilde uitbreiden. De slaven wilden nu ,de Hoop" niet verlaten. Dat was van velen hunner de geboorteplaats en daaraan waren zij zeer gehecht. De opzichter meende, dat geweld zou moeten worden gebruikt; de heer Copiers was echter van een tegenovergesteld gevoelen en beloofde den volgenden dag alleen op de plantage te komen. Ver Huell bood aan hem te vergezellen, welk aanbod werd aangenomen, doch beducht voor de veiligheid van den heer Copiers liet Ver Huell de tentboot door een gewapende sloep van zijn brik volgen, toen beiden zich naar de plantage ,dde Hoop" begaven. Bij aankomst bespeurden zij een groote opschudding doch Copiers liet met de grootste bedaardheid allen onder het balcon van de plantagewoning oproepen. Hij zette uiteen, dat de bodem te veel door de cultuur was uitgeput en dat het daarom noodig was, dat een groot deel van de bevolking zich naar „Providence” begaf. De slaven bleven echter met luid geschreeuw in hun weigering volharden. Nu liet hij eenigen van de oudsten voor zich komen, vroeg hen of zij niet redenen hadden om tevreden te zijn, of hij hun immer iets liet ontbreken, of hij niet alle mogelijke zorg voor hen droeg, wanneer zij ziek waren? en meer andere vragen, die alle met een volmondig ,,ja" werden beantwoord. Welnu, vervolgde hij, staat het mij niet vrij een andere plantage in cultuur te brengen tot mijn voordeel, waar gij even goed behandeld zult worden, beter woningen zult vinden en een in alle opzichten betere plaats voor uw gezinnen? Deze bedaarde wijze om hen te overtuigen, dat zij ongelijk hadden, had dit gevolg, dat na eenige woordenwisseling onder elkander dadelijk een groot gedeelte van de slaven zich in de tentbooten inscheepte en met pak en zak vertrok. Naderhand volgden alle overigen, en de orde bleef volkomen hersteld. 
Ver Huell achtte dit een sprekend bewijs hoezeer menschelijkheid en gepaste standvastigheid een heilzame invloed, ook op deze menschen kunnen uitoefenen. Ware hier geweld gebruikt, dan zou de zaak niet zonder bloedvergieten afgeloopen zijn. Hij was yan oordeel, dat, wanneer alle planters dit edel voorbeeld volgden, veel onheil voorkomen zou worden.

Ver Huell ondernam een tocht naar Essequebo en voer daar met een tentboot de rivier op tot aan de watervallen. Hij was opgetogen over de hem omringende natuur en genoot gastvrijheid bij een zeer bejaard gewezen planter en zijn gezin, zooals in Europa niet bestaat. Het hoofd des huizes had eenmaal een uitgestrekte plantage bezeten, die zeer veel opbracht, maar daar alle plantages aan de bovenrivier verlaten waren, leverde zij toen niet meer op, dan tot levensonderhoud van zijn talrijk huisgezin kon dienen. Den volgenden morgen begaf V.H. zich met gezelschap naar de watervallen, waarvan hij het gedruisch den ganschen nacht gehoord had. Door de dichte boomen met slingers en parasietplanten aan elkaar verbonden, kon men den waterval eerst zien toen men zeer nabij was. Plotseling ontplooide zich een schouwspel dat V.H. opgetogen deed stilstaan. Langs naakte rotsen stortte het water in sneeuwwitte, schuimende vlokken met een geweldig gedruisch naar beneden. Bloeiende boomen slingerden overal hun dichte kruinen door elkander, en festoenen van lianen zwierden door den wind heen en weder. De waterval is in twee afdeelingen verdeeld met een kom kristalhelder water tusschen beiden, verder stroomt hij over groote rotsblokken schuimend voort. Het gezang weerklonk van talrijke vreemde vogels, wier kleurenpracht schitterde in de eerste stralen der morgenzon. Een zonnevisch schitterend als zilver stortte van den eersten waterval naar beneden en werd in de kalme kom door een Indiaan behendig geharpoeneerd. Het was een groote visch met glinsterende schubben, die een smakelijk gerecht voor het ontbijt beloofde.

Nadat V. H. naar Demerary was teruggekeerd, viel daar het fregat Aliantie onder bevel van kapitein Spengler binnen, die hem dadelijk zijn bevreemding te kennen gaf, dat hij hem niet naar Curaçao was gevolgd. Een ter zake gerezen twist bracht een groote koelheid tusschen beide bevelhebbers teweeg. In verband met ongunstige berichten uit het moederland begon men er op bedacht te worden den staat van tegenweer der kolonie zooveel mogelijk te versterken. Men kon echter niet meer doen, dan gewapende koopvaarders met de beide oorlogschepen op de rivier 
in den voordeeligsten stand plaatsen en de batterijen zooveel doenlijk in staat van tegenweer brengen. Gelukkig bleken later deze voorzorgen onnoodig te zijn geweest. Het verwonderde Ver Huell echter dat hier, zoowel als in de andere volksplantingen het defensie-wezen zoo schromelijk verwaarloosd was, men kon duidelijk bemerken, zegt hij, dat alleen kooplieden het hoofdbestuur daarvan in handen hadden.

Kapitein Spengler besloot nu, daar de victualietijd van de schepen ten einde liep, naar het vaderland terug te keeren en de koopvaarders onder konvooi te nemen. Ver Huell werd gelast de achterhoede te dekken en betoonde bij die moeielijke taak (vele koopvaarders zeilden slecht en het was moeilijk die gedurende den nacht bij elkander te houden) zooveel ijver, dat kapitein Spengler hem herhaaldelijk zijn groote tevredenheid betuigde, waardoor een vriendschappelijker verhouding ontstond. De reis was moeilijk en lang; er ontstond gebrek aan levensmiddelen, maar Ver Huell trachtte door zijn voorbeeld allen tot geduld op te wekken. Hij vermocht dit te doen, schrijft hij, door den troost van zijn godsdienstig geloof. Iederen Zondag hield hij godsdienstoefening met zijn bemanning. $\mathrm{Na}$ drie maanden viel het voltallig gebleven konvooi Texel binnen; de bemanning van de Pijl was gezond en sterk gebleven, in weerwil van de benarde reis.

Ver Huell vond bij aankomst zijn aanstelling tot kapiteinluitenant ter zee. Hij bracht zijn bodem naar Amsterdam om het schip aldaar te doen herstellen. Daarna begaf hij zich naar zijn woning te Doetinchem, waar hij door zijn vrouw en hun beide zoontjes met groote vreugde werd ontvangen.

Naschrift.

Ver Huell heeft nog twee opmerkingen over Indianen in Guyana gemaakt, die min of meer de meening van zijn tijdgenooten vertolken, maar die naar de tegenwoordige opvattingen onjuist zijn, dan wel feiten weergeven die onder een ander licht dienen te worden bezien. Het is leerzaam en van belang bij die opmerkingen stil te staan, ze te belichten en ze zooveel mogelijk aan te vullen of te verbeteren.

Het eenige, zoo zeide V. H., wat de Indianen van de meer beschaafde volken hebben overgenomen, is de onbedwingbare lust, zich door sterke en verhittende dranken tot dronkenschap toe op te winden.

Degenen, die in de encyclopaedie van Nederlandsch West-Indië kennis heeft genomen, van hetgeen daar onder de woorden 
Indianen (genotmiddelen) en Kassave wordt medegedeeld, weet dat de Indianen zelf bedwelmende dranken, kassiri en tapanà, bereiden. Over drinkgelagen vinden wij in de encyclopaedie telkens even gewag gemaakt; op blz. 109, 2de kolom en blz. 116, le kolom; voorts op blz. 172, 2de kolom. Op blz. 496, 2de kolom staat van ons aangehaald: „Les Indiens, ivres comne l'exige leur loi". Uit het weinige wat ervan staat, en uit het onderling verband, kan men reeds opmaken, dat de Indianen al vóór de komst van de blanke ontdekkers gewoon waren zich door sterke dranken ,"tot dronkenschap toe op te winden" (en de lust daartoe dus niet van meer beschaafde volken behoefden over te nemen). Maar er is aan dit onderwerp toch meer verbonden, en het komt ons voor dat de encyclopaedie op dit punt eenige aanvulling verdient. De Indiaan bezit, helaas, geen weerstand tegen de verleiding van de door ons samengestelde sterke dranken. Hij drinkt zich aan onzen sterken drank (wanneer hij die bekomen kan) dood. In het bekende ,Ethnographisches und Verwandtes aus Guayana”" van Prof. Dr. Joest zal men op dit gebied een schildering vinden, die elken Europeaan het schaamrood naar het hoofd jaagt.

Men zal uitvoerige gegevens vinden over den strijd tegen het drankmisbruik van Indianen, ondernomen door de R.K. geestelijkheid, in het artikel „Les sauvages du Canada et les maladies ,,importées de France au XVIIe et au XVIII siècle:,,La Picote et l'alcoolisme", par Emile Salone, blz. 7-20 van het Journal de la Société des Américanistes de Paris, Nouvelle Serie, Tome IV, no. 1, 1907. Daarin staat: l'alcoolisme prépare la voie à la tuberculose" en wordt als vaststaand aangenomen dat op die wijze de Indianen uitsterven.

Wij verzoeken, dat in den nieuwen druk van de encyclopaedie ook dit onderwerp moge worden besproken. Het zou aardig zijn, indien kon worden vastgesteld, dat het koloniaal bestuur, dan wel de zending en de R.K. Missie, er in zouden zijn geslaagd bezwaren te overkomen, die indertijd zelfs den staatsman Colbert (blijkens het aangehaalde artikel) moeite hebben verschaft.

De tweede opmerking van Ver Huell is: dat de natuur den Indianen ,schatten in overvloed"' aanbiedt; de rivieren hun visch schenken, de wouden gevogelte en visch. Hij verbouwt slechts cassave.

Wij noorderlingen, bewoners van de gematigde zône, waar het leven in materieel opzicht ons zwaar voorkomt, zijn maar al te zeer geneigd om aan te nemen dat tropische volken een min of meer paradijselijk bestaan voeren. Zoo zegt Dr. Paul Julien in 
zijn in 1940 uitgekomen boek „Kampvuren langs den evenaar”, blz. 239. Zwaar, bovenmate zwaar is echter de taak van den tropischen landbouwer. Reeds de ontginning van een terrein kost er onevenredig zwaarder arbeid, dan in de gematigde zone. De ontginningstrijd is voor den tropenbewoner een steeds weerkeerende kamp. Met ongeloofelijke snelheid groeit op een terrein, dat korten tijd braak heeft gelegen, een nieuwe, secundaire vegetatie op. In de tropen hebben jonge en rijpende gewassen oneindig veel meer dan in onze streken te lijden van ziekten en insektenplagen. Wij weten van een geval dat een cassave-aanplanting aan de Marowijne-rivier door mieren volkomen werd verwoest. In enkele jaren kan secundaire plantengroei den omvang van zwaar bosch hebben bereikt, en wat er noodig is om met gegebrekkige werktuigen bosch te vellen, kan men zich voorstellen.

Voorts is het wel bekend dat de Europeaan, die in het oerwoud verdwaalt van honger sterft. Hoeveel vernuft, kunde, ondernemingszin en ijver er voor den Indiaan noodig is om de schatten, die de natuur hem zoogenaamd schenkt, te verwerven, daarvan krijgt men een inzicht door lezing van de artikelen over beneden- en bovenlandsche Indianen in de aangehaalde encyclopedie.

Wij mogen niet verheelen dat daarin op blz. 116, 1ste kolom onderaan staat, dat de zoogenaamde vreedzaamheid en zachtaardigheid waarschijnlijk voor een deel zijn te verklaren uit onverschilligheid en apathie, en dat op blz. 115, 2de kolom, dr. H. ten Kate in één snijdend zinnetje toch wel degelijk gezegd heeft, dat het verregaande misbruik van sterken drank den Indiaan te gronde richt. Evenmin, dat er op blz. 108, 1ste kolom wordt medegedeeld, dat de veelwijverij veel minder is dan vroeger, en dat op blz. 173, 1ste kolom deze zinsnede voorkomt: Polygamie is algemeen in zwang. V. H. kan dus tot op zekere hoogte gelijk hebben gehad, en het zou verkeerd kunnen zijn de vreedzaamheid en zachtaardigheid als kenmerk van Indiaansche beschaving te hoog aan te slaan. 